\title{
PENGENDALIAN KUALITAS PRODUK COMPOUND AT-807 DI PLANT MIXING CENTER DENGAN METODE SIX SIGMA PADA PERUSAHAAN BAN DI JAWA BARAT
}

\author{
SRI LESTARI, ${ }^{1)}$ \& MOCHAMAD HASAN JUNAIDY ${ }^{2)}$ \\ ${ }^{1,2)}$ Program Studi Teknik Industri, Fakultas Teknik, \\ Universitas Muhammadiyah Tangerang \\ Jl. Perintis Kemerdekaan I/33, Cikokol, Kota Tangerang \\ Email: srilestari2606@gmail.com ${ }^{1)}$,Mochamadhasan95@gmail.com ${ }^{2)}$
}

\begin{abstract}
ABSTRAK
Kualitas adalah target utama dalam pembuatan suatu produk. kualitas produk yang dihasilkan adalah cerminan keberhasilan perusahaan dimata konsumen. Pengendalian kualitas perlu dilakukan dikarenakan kualitas memiliki tujuan untuk menjaga, mengarahkan, mempertahankan, dan meningkatkan kualitas produk agar tetap sesuai dengan standart yang telah ditetapkan. Perusahaan ban di Jawa Barat sebagai salah satu perusahaan yang bergerak di bidang produksi berbagai jenis ban kendaraan bermotor, mobil, maupun bus dan truck di Indonesia yang dihasilkan disebarkan ke banyak daerah di Indonesia maupun di mancanegara, yang berada di Tangerang-Banten. Metode peningkatan kualitas salah satunya adalah Six Sigma. Six Sigma memiliki fokus pada mengurangi tingkat cacat, dengan mencapai standar 3,4 cacat perjuta peluang, Six Sigma memiliki 5 fase, Define, Measure, Analyze, Improvement dan Control (DMAIC). Pada penelitian ini, Six Sigma di terapkan di bagian plant mixing center yang memproduksi compound AT-807, dengan tujuan untuk menganalisis pengendalian kualitas dan meningkatkan kualitas dengan cara mengatasi dan mengurangi banyaknya cacat yang timbul sehingga diharapkan adanya perbaikan pada produk yang dihasilkan. Perubahan yang sangat jelas terjadi dari sebelum perbaikan dan sesudah perbaikan yang dapat peneliti rasakan dengan adanya perbaikan ini perusahaan dapat menghemat pengeluaran reject compound yang sebelumnya perusahaan dapat rugi dengan kisaran nominal uang sebesar 6,6 Milyar dan dengan adanya perubahan perbaikan ini perusahaan dapat mengehamat biaya reject dengan sebesar 4,9 Milyar menjadi 1,7 Milyar, dan adanya perubahan perbaikan ini jumlah reject berkurang, dari yang rata-rata reject sebanyak 1910 batch dapat ditekan menjadi 481 batch.
\end{abstract}

Kata Kunci: Kualitas, Pengendalian Kualitas, Six Sigma, Quality Improvement, $5 \mathrm{~W}+1 \mathrm{H}$

\section{PENDAHULUAN}

Suatu perusahaan tidak lepas dari konsumen serta produk yang dihasilkannya. Konsumen tentunya berharap bahwa barang yang dibelinya akan dapat memenuhi kebutuhan dan keinginannya sehingga konsumen berharap bahwa produk tersebut memiliki kondisi yang baik serta terjamin. Oleh karena itu perusahaan harus melihat serta menjaga agar kualitas produk yang dihasilkan terjamin serta diterima oleh konsumen serta dapat bersaing di pasar.

Pengendalian kualitas yang dilaksanakan dengan baik akan memberikan dampak terhadap mutu produk yang dihasilkan oleh perusahaan. Kualitas dari produk yang dihasilkan oleh suatu perusahaan ditentukan berdasarkan ukuran- ukuran dan karakteristik tertentu. Walaupun proses-proses produksi telah dilaksanakan dengan baik, namun pada kenyataan masih ditemukan terjadinya kesalahan-kesalahan dimana kualitas produk yang 
dihasilkan tidak sesuai dengan standar atau dengan kata lain produk yang dihasilkan mengalami kerusakan atau cacat pada produk.

Standar kualitas yang dimaksud adalah bahan baku, proses produksi, dan produk jadi. Oleh karenanya, kegiatan pengendalian kualitas tersebut dapat dilakukan mulai dari bahan baku, selama proses produksi berlangsung sampai pada produk akhir dan disesuaikan dengan standar yang ditetapkan.

Banyak sekali metode yang mengatur atau membahas mengenai kualitas dengan karakteristiknya masing-masing. Six sigma sebagai salah satunya, metode six sigma adalah metode baru yang paling popular merupakan salah satu alternatif dalam prinsipprinsip pengendalian kualitas yang berupa terobosan dalam bidang manajemen kualitas. Six sigma dapat dijadikan ukuran kinerja sistem industri yang memungkinkan perusahaan melakukan peningkatan yang luar biasa dengan terobosan strategi yang aktual. Six sigma juga dapat dipandang sebagai pengendalian proses industri yang berfokus pada pelanggan dengan memerhatikan kemampuan proses. Pencapaian six sigma hanya terdapat 3,4 cacat per sejuta kesempatan. Semakin tinggi target sigma yang dicapai maka kinerja sistem industri semakin membaik.

Perusahaan ban terkenal di jawa barat sebagai salah satu perusahaan yang bergerak di bidang produksi berbagai jenis ban kendaraan bermotor, mobil, bus maupun truck. Permintaan pasar terhadap hasil produksi perusahaan tersebut selalu tinggi di pasaran. Oleh karena itu, kualitas produk yang dihasilkan harus di jaga agar pelanggan merasa puas menggunakan produk tersebut. Kualitas ban yang dihasilkan cukup memuaskan di pasaran, namun salah satu kendala adalah kualitas compound yang tidak memenuhi standar sehingga hasil produksi yang dihasilkan tidak sesuai dengan target produksi. Compound adalah hasil proses dari proses mixing atau pencampuran yang terdiri dari bahan baku yaitu karet, oil, black carbon, silica, zinc oxide dan chemical. Compound merupakan bahan baku yang berupa lembaran yang digunakan pada semua proses pembuatan ban.

\section{METODE PENELITIAN}

Untuk melakukan penelitian guna mendapatkan tujuan yang diinginkan maka dila- kukan beberapa langkah-langkah sebagai berikut:

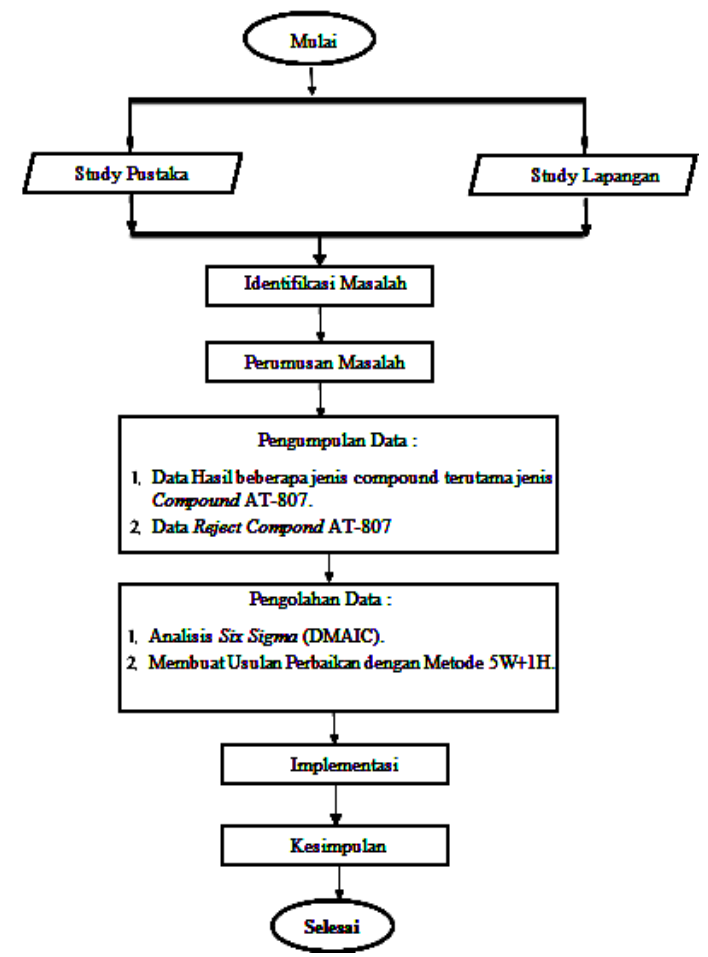

Gambar 1. Diagram alir penelitian.

\section{HASIL DAN PEMBAHASAN}

\section{Tahap Define}

Pada tahap ini adalah proses mendefinisikan masalah standar kualitas atau critical to quality (CTQ).

Tabel 1. Compond Reject Mixing Center Juli-Desember 2018

\begin{tabular}{|c|c|c|c|c|c|c|c|c|c|c|}
\hline \multirow[b]{2}{*}{0} & \multirow{2}{*}{\begin{tabular}{|l|} 
IIIEM \\
Type \\
\end{tabular}} & \multicolumn{6}{|c|}{ PERIODE } & \multirow{2}{*}{ TOTAL } & \multirow{2}{*}{ PERSENTASE } & \multirow{2}{*}{ ACCUM } \\
\hline & & Jul-18 & Agu-18 & Sep-18 & 0 kt-18 & Nov-18 & Des-18 & & & \\
\hline 1 & AT 807 & 1915 & 1911 & 1874 & 1823 & 2322 & 1616 & 11461 & $43,03 \%$ & $43,03 \%$ \\
\hline 2 & AT-811 & 771 & 529 & 821 & 453 & 313 & 655 & 3542 & $3,30 \%$ & $56,33 \%$ \\
\hline 3 & AT-881 & 887 & 428 & 668 & 781 & 89 & 81 & 2934 & $1,02 \%$ & $6735 \%$ \\
\hline 4 & AT -803 & 676 & 621 & 782 & 555 & 84 & 104 & 2822 & $10,60 \%$ & $77,94 \%$ \\
\hline 5 & AT-811 & 541 & 511 & 307 & 1141 & 14 & 12 & 2526 & $9,48 \%$ & $87,43 \%$ \\
\hline 6 & AT- 819 & 432 & 124 & 91 & 121 & 14 & 331 & 1113 & $4,18 \%$ & $91,61 \%$ \\
\hline 7 & AT-817 & 334 & 218 & 163 & 211 & 104 & 98 & 1128 & $4,24 \%$ & $95,84 \%$ \\
\hline 8 & AT -813 & 112 & 102 & 88 & 92 & 78 & 56 & 528 & $1,98 \%$ & $97,82 \%$ \\
\hline 9 & AT- 878 & 85 & 51 & 47 & 8 & 112 & 141 & 444 & $1,67 \%$ & $99,49 \%$ \\
\hline 10 & AT-884 & 11 & 26 & 35 & 16 & 12 & 34 & 134 & $0,50 \%$ & $100,00 \%$ \\
\hline & 26632 & $100 \%$ & \\
\hline
\end{tabular}

Tabel 2. Data Jumlah Produksi dan Reject Compound AT-807 Periode Bulan Juli - Desember 2018

\begin{tabular}{|c|c|c|c|}
\hline BULAN & $\begin{array}{c}\text { JUMLAH } \\
\text { PRODUKSI }\end{array}$ & $\begin{array}{c}\text { JUMLAH } \\
\text { REJECT }\end{array}$ & PERSENTASE \\
\hline Jul-18 & 5115 Batch & 1915 Batch & $37,44 \%$ \\
\hline Agu-18 & 5321 Batch & 1911 Batch & $35,91 \%$ \\
\hline Sep-18 & 5288 Batch & 1874 Batch & $35,44 \%$ \\
\hline Okt-18 & 5062 Batch & 1823 Batch & $36,01 \%$ \\
\hline Nov-18 & 5710 Batch & 2322 Batch & $40,67 \%$ \\
\hline Des-18 & 5421 Batch & 1616 Batch & $29,81 \%$ \\
\hline TOTAL & 31917 Batch & 11461 Batch & $215,28 \%$ \\
\hline Rata-rata & 5319,50 & 1910,17 & $35,88 \%$ \\
\hline
\end{tabular}


Tabel 3. CTQ (Critical to Quality)

\begin{tabular}{|c|c|l|}
\hline No & ITEM KRITERIA REJECT & \multicolumn{1}{|c|}{ KETERANGAN } \\
\hline 1 & Viskositas & $\begin{array}{l}\text { Kekenyalan pada compound tidak } \\
\text { memasuki standart batas toleransi }\end{array}$ \\
\hline 2 & Kasar & $\begin{array}{l}\text { Permukaan compound Kasar dan } \\
\text { Permukaan compound tidak rata }\end{array}$ \\
\hline 3 & Sheet Over Tebal & $\begin{array}{l}\text { Sheet Over tebal tidak memenui standart } \\
\text { yaitu 6-10 Mm }\end{array}$ \\
\hline 4 & Lengket & $\begin{array}{l}\text { Compound Lengket antara tumpukan per- } \\
\text { batch }\end{array}$ \\
\hline 5 & Sheet Sobek $>5 \mathrm{Cm}$ & $\begin{array}{l}\text { Sheet sobek tidak memenhui standart batas } \\
\text { maximal 5 Cm }\end{array}$ \\
\hline 6 & Blister & $\begin{array}{l}\text { Permukaan compound bergelembung dan } \\
\text { compound berlubang }\end{array}$ \\
\hline 7 & Terkontaminasi & $\begin{array}{l}\text { Compound terkontaminas dan di dalam } \\
\text { compound terdapat kayu, besi, plastik dll }\end{array}$ \\
\hline 8 & Scorch/Terbakar & $\begin{array}{l}\text { Permukaan compound tidak rata dan ada } \\
\text { benjolan keras pada permukan compound }\end{array}$ \\
\hline
\end{tabular}

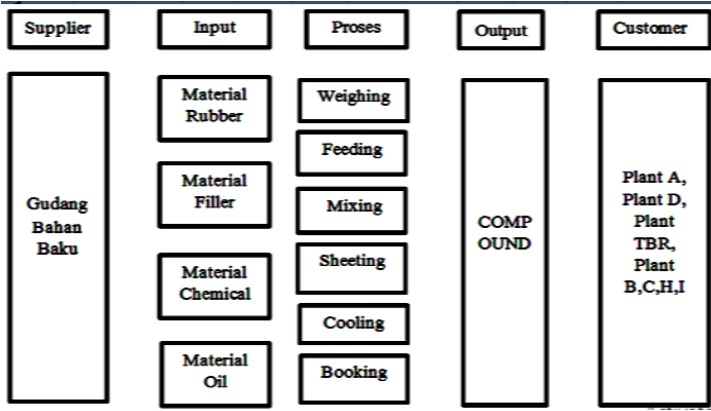

Gambar 2. SIPOC Pembuatan Compound.

\section{Tahap Measure}

Measure merupakan tahap pengevaluasian sistem pengukuran dan menafsir kemampuan baseline kinerja (output) dari perusahaan ban.

Tabel 4. Karakteritik Kulitas Kunci (CTQ) Produk Compound AT-807

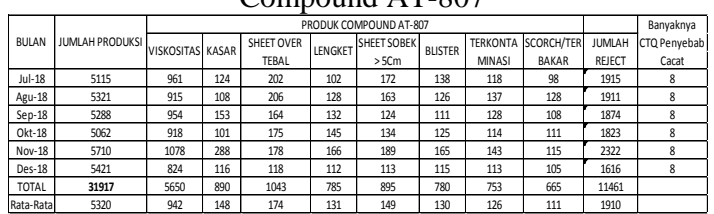

Tabel 5. Peritungan Peta $\mathrm{p}$

\begin{tabular}{|c|c|c|c|c|c|c|}
\hline BULAN & $\begin{array}{c}\text { JUMLAH } \\
\text { PRODUKSI }\end{array}$ & $\begin{array}{c}\text { JMLAH } \\
\text { REJECT }\end{array}$ & P & p-bar & UCL & LCL \\
\hline Jul-18 & 5115 & 1915 & $\mathbf{0 , 3 7 4 3 8 9 0 5}$ & 0,35908763 & $\mathbf{0 , 3 7 9 2 1 0 8 8}$ & $\mathbf{0 , 3 3 8 9 6 4 4}$ \\
\hline Agu-18 & 5321 & 1911 & $\mathbf{0 , 3 5 9 1 4 3 0 2}$ & 0,35908763 & $\mathbf{0 , 3 7 8 8 1 7 5 0}$ & $\mathbf{0 , 3 3 9 3 5 7 8}$ \\
\hline Sep-18 & 5288 & 1874 & $\mathbf{0 , 3 5 4 3 8 7 2 9}$ & 0,35908763 & $\mathbf{0 , 3 7 8 8 7 8 9 7}$ & $\mathbf{0 , 3 3 9 2 9 6 3}$ \\
\hline Okt-18 & 5062 & 1823 & $\mathbf{0 , 3 6 0 1 3 4 3 3}$ & 0,35908763 & $\mathbf{0 , 3 7 9 3 1 5 9 5}$ & $\mathbf{0 , 3 3 8 8 5 9 3}$ \\
\hline Nov-18 & 5710 & $\mathbf{2 3 2 2}$ & $\mathbf{0 , 4 0 6 6 5 4 9 9}$ & 0,35908763 & $\mathbf{0 , 3 7 8 1 3 3 5 9}$ & $\mathbf{0 , 3 4 0 0 4 1 7}$ \\
\hline Des-18 & 5421 & 1616 & $\mathbf{0 , 2 9 8 0 9 9 9 8}$ & 0,35908763 & $\mathbf{0 , 3 7 8 6 3 4 6 8}$ & $\mathbf{0 , 3 3 9 5 4 0 6}$ \\
\hline TOTAL & 31917 & 11461 & $\mathbf{0 , 3 5 9 0 8 7 6 3}$ & 0,35908763 & $\mathbf{0 , 3 6 7 1 4 3 4 5}$ & $\mathbf{0 , 3 5 1 0 3 1 8}$ \\
\hline Rata-rata & 5319,50 & 1910,17 & & & & \\
\hline
\end{tabular}

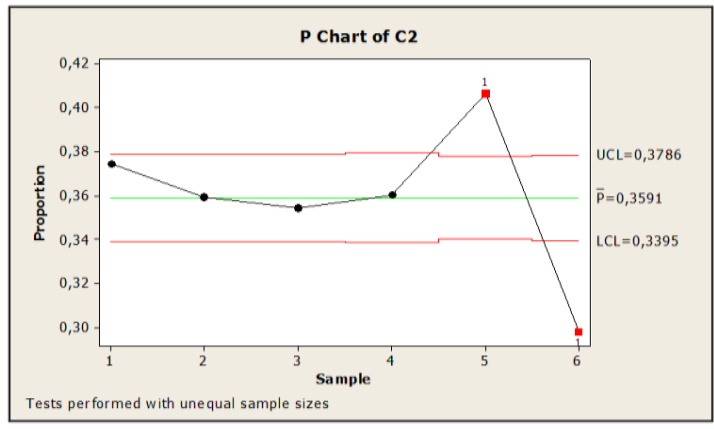

Gambar 3. Peta Kendali P Produk Compound.
Tabel 6. Rekapitulasi Nilai DPMO,

Nilai Sigma $(\boldsymbol{\sigma})$ dan Yeild

\begin{tabular}{|c|c|c|c|c|c|c|}
\hline Bulan & $\begin{array}{c}\text { Jumlah } \\
\text { Produksi }\end{array}$ & $\begin{array}{c}\text { Jumlah } \\
\text { Reject }\end{array}$ & $\begin{array}{c}\text { DPU } \\
\text { (Deffect Per } \\
\text { Unit) }\end{array}$ & $\begin{array}{c}\text { DPMO (Deffect } \\
\text { per Million } \\
\text { Opportunities) }\end{array}$ & $\begin{array}{c}\text { Level } \\
\text { Sigma }\end{array}$ & Yield \\
\hline Jul-18 & 5115 & 1915 & $\mathbf{0 , 0 4 6 7 9 8 6 3 1}$ & $\mathbf{4 6 7 9 8 , 6 3}$ & 3,18 & $63 \%$ \\
\hline Agu-18 & 5321 & 1911 & $\mathbf{0 , 0 4 4 8 9 2 8 7 7}$ & $\mathbf{4 4 8 9 2 , 8 8}$ & 3,20 & $64 \%$ \\
\hline Sep-18 & 5288 & 1874 & $\mathbf{0 , 0 4 4 2 9 8 4 1 1}$ & $\mathbf{4 4 2 9 8 , 4 1}$ & 3,20 & $\mathbf{6 5 \%}$ \\
\hline Okt-18 & 5062 & 1823 & $\mathbf{0 , 0 4 5 0 1 6 7 9 2}$ & $\mathbf{4 5 0 1 6 , 7 9}$ & 3,20 & $\mathbf{6 4 \%}$ \\
\hline Nov-18 & 5710 & 2322 & $\mathbf{0 , 0 5 0 8 3 1 8 7 4}$ & 50831,87 & 3,14 & $59 \%$ \\
\hline Des-18 & 5421 & 1616 & $\mathbf{0 , 0 3 7 2 6 2 4 9 8}$ & 37262,50 & 3,29 & $70 \%$ \\
\hline TOTAL & $\mathbf{3 1 9 1 7}$ & 11461 & & & & \\
\hline RATA-RATA & 5319,50 & 1910,17 & $\mathbf{0 , 0 4 4 8 5 0 1 8 1}$ & 44850,18061 & 3,20 & \\
\hline
\end{tabular}

\section{Tahap Analyze}

Tahap analyze merupakan tahap ketiga dalam metode six sigma. Pada tahap ini dilakukan eksplorasi data untuk mengetahui keadaan yang ada pada saat ini, analisa data untuk membuat kesimpulan atas data yang ada identifikasi dan verifikasi penyebab masalah, kemudian mengidentifikasi kemungkinan perbaikan yang dapat dilakukan.

Tabel 7. Frekuensi CTQ Produk Compound AT-807

\begin{tabular}{|c|c|c|c|r|r|}
\hline No & ITEM KRITERIA & $\begin{array}{c}\text { Frekuensi } \\
\text { Reject }\end{array}$ & $\begin{array}{c}\text { Frekuensi } \\
\text { Kumulatif Reject }\end{array}$ & Persentase & ACCUM \\
\hline 1 & Viskositas & 5650 & 5650 & $49 \%$ & $49 \%$ \\
\hline 2 & Sheet Over Tebal & 1043 & 6693 & $9 \%$ & $58 \%$ \\
\hline 3 & Sheet Sobek $>5 \mathrm{Cm}$ & 895 & 7588 & $8 \%$ & $66 \%$ \\
\hline 4 & Kasar & 890 & 8478 & $8 \%$ & $74 \%$ \\
\hline 5 & Lengket & 785 & 9263 & $7 \%$ & $81 \%$ \\
\hline 6 & Blister & 780 & 10043 & $7 \%$ & $87 \%$ \\
\hline 7 & Terkontaminasi & 753 & 10796 & $7 \%$ & $94 \%$ \\
\hline 8 & Scorch/ Terbakar & 665 & 11461 & $6 \%$ & $100 \%$ \\
\hline \multicolumn{7}{|c|}{ TOTAL } & 11461 & & & \\
\hline
\end{tabular}

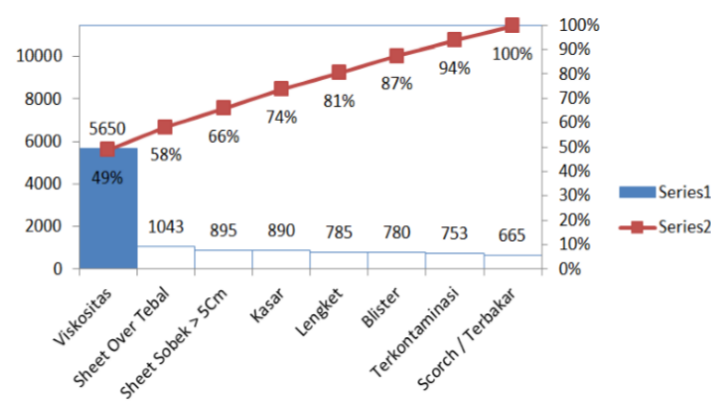

Gambar 4. Frekuensi CTQ Produk Compound AT-807

a) Analisa Kondisi yang Ada

Menggunakan Methode QCDSMP

(Quality, Cost, Delivery, Safety, Moral, Productivity) sebagai berikut:

[1] Q (Quality) = Problem compound AT807 rata-rata 1910 batch selama bulan dari periode Juli 2018 sampai dengan Desemeber 2018

[2] $\mathrm{C}($ Cost $)=$ Biaya Reproses problem compound AT-807 dengan harga compound $\mathrm{Rp} .3 .500 .000$ perbatch $\mathrm{x}$ rata-rata reject selama periode Juli 2018 sampai dengan Desember 2018 dengan rata-rata 1910 Batch, jadi Rp. 3.500 .000 x $1910=$ 
Rp. 6,6 Milyar, karena per-batch dengan jumlah berat compound $300 \mathrm{~kg}$ dan harga per-kg seharga Rp. 11.600

[3] $\mathrm{D}$ (Delivery) = Pengiriman ke step proses selanjutnya terlambat

[4] $\mathrm{S}($ Safety $)=$ Tidak berpengaruh

[5] $\mathrm{M}($ Moral $)=$ Untuk kerja team produksi kurang peduli dengan hasil reject yang ditimbulkan

[6] $\mathrm{P}$ (Productivity) = Produktivitas $\mathrm{di}$ proses selanjutnya terganggu karena terjadinya compound AT-807 reject.

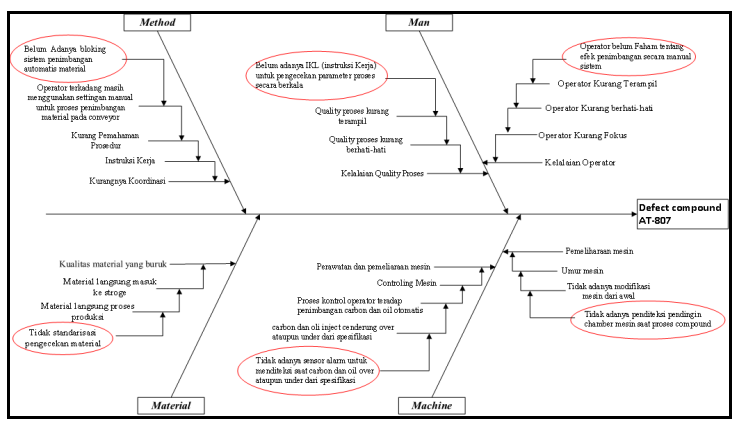

b) Menetapkan Target

Menggunakan metode SMART (Speci-

fik, Measurable, Achievable, Reasonable,

Time Frame).

[1] Specifik (Fokus pada permasalahan) = Compound reject AT-807 dengan pro-blem viskositas yang paling tertinggi.

[2] Measurable (Target yang dapat diukur) = Menurunkan compound reject AT-807 menjadi 500/bulan.

[3] Achievable (Acuan untuk mencapai tar-get) $=$ Rata-rata reject 1910 batch/bu-lan menjadi $500 \mathrm{batch} / \mathrm{bulan}$ pada compound AT- 807 .

[4] Reasonable (Alasan masuk akal) = Berdasarkan penelitian ini akan diturunkan menjadi $500 \mathrm{batch} / \mathrm{bulan}$.

[5] Time Frame (Waktu yang dibutuhkan) = diselesaikan sampai akhir bulan Maret 2019.
Tabel 8. Menetapkan Target

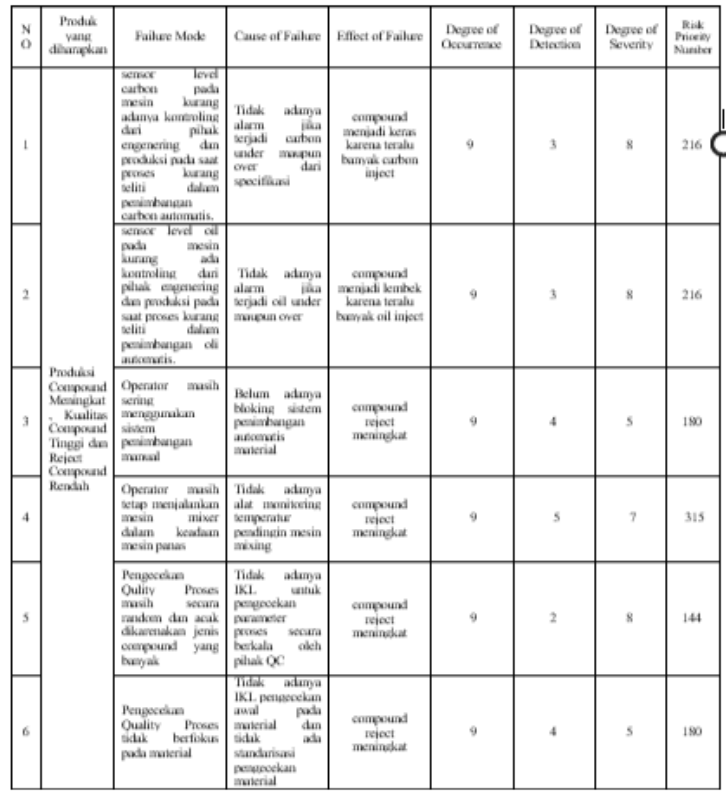

Tabel 9. Menetapkan Target

\begin{tabular}{|c|c|c|c|}
\hline No & ITEM & $\begin{array}{c}\text { KONDISI SEBELUM } \\
\text { IMPROVE }\end{array}$ & $\begin{array}{c}\text { TARGET SETELAH } \\
\text { IMPROVE }\end{array}$ \\
\hline 1 & $\begin{array}{c}\text { Rata-Rata Jumlah } \\
\text { Produksi }\end{array}$ & 5319 Batch & 5319 Batch \\
\hline 2 & $\begin{array}{c}\text { Rata-Rata Reject } \\
\text { compound AT-807 }\end{array}$ & 1910 Batch & 500 Batch \\
\hline \multicolumn{2}{|r|}{ Persentase } & $35,9 \%$ & $9,4 \%$ \\
\hline
\end{tabular}

\section{Tahap Improve}

Pada tahap ini yang dilkukan adalah menetapkan rencana-rencana tindakan untuk melaksanakan peningkatan kualitas menggunakan metode Six Sigma, Berdasarkan 5W+1H (What-Tujuan Utama, WhyAlasan, Where-Lokasi, When-Waktu, WhoOrang, How-Metode). Rencana tindakan atau usulan-usulan pada faktor man, material, method dan machine untuk jenis produk compound AT-807 dengan problem viskositas.

Tabel 10. Usulan Perbaikan Menggunakan Metode $5 \mathrm{~W}+1 \mathrm{H}$

\begin{tabular}{|c|c|c|}
\hline Jenis & $5 \mathrm{~W}+1 \mathrm{H}$ & Deskrpsi Rencana Perbaikan \\
\hline $\begin{array}{l}\text { Tujuan } \\
\text { Utama }\end{array}$ & What (Apa) & Menurunkan reject compound AT-807 \\
\hline $\begin{array}{c}\text { Alasan } \\
\text { Kegunaan }\end{array}$ & $\begin{array}{c}\text { Why } \\
\text { (Mengapa) }\end{array}$ & $\begin{array}{l}\text { Agar Proses Produksi sesuai dengan prosedur kerja } \\
\text { yang telah ditetapkan sehingga mengasilkan produk } \\
\text { baik tanpa reject dan sesuai spesifikasi }\end{array}$ \\
\hline Lokasi & $\begin{array}{l}\text { Where } \\
\text { (Dimana) }\end{array}$ & $\begin{array}{l}\text { Dilaksanakan di Perusaaan ban di Jawa Barat, } \\
\text { tepatnya di ruang area produksi }\end{array}$ \\
\hline $\begin{array}{l}\text { Sekuens } \\
\text { (Urutan) }\end{array}$ & $\begin{array}{l}\text { When } \\
\text { (Kapan) }\end{array}$ & Pada saat proses produksi \\
\hline Orang & Who (Siapa) & $\begin{array}{l}\text { Tanggung jawab diserakan kepada operator produksi, } \\
\text { engenering }\end{array}$ \\
\hline Metode & $\begin{array}{c}\text { How } \\
\text { (Bagaimana) }\end{array}$ & $\begin{array}{l}\text { Pemasangan alat monitoring tempexatur pendingin } \\
\text { mesin }\end{array}$ \\
\hline
\end{tabular}


Tabel 11. Usulan Perbaikan Menggunakan Metode $5 \mathrm{~W}+1 \mathrm{H}$

\begin{tabular}{|c|c|c|}
\hline Jenis & $5 \mathrm{~W}+1 \mathrm{H}$ & Deskrpsi Rencana Perbaikan \\
\hline $\begin{array}{c}\text { Tujuan } \\
\text { Utama }\end{array}$ & What (Apa) & Menurunkan reject compound AT-807 \\
\hline $\begin{array}{c}\text { Alasan } \\
\text { Kegunaan }\end{array}$ & $\begin{array}{c}\text { Why } \\
\text { (Mengapa) }\end{array}$ & $\begin{array}{c}\text { Agar Proses Produksi sesuai dengan prosedur kerja } \\
\text { yang telah ditetapkan sehingga mengasilkan produk } \\
\text { baik tanpa reject dan sesuai spesifikasi }\end{array}$ \\
\hline Lokasi & $\begin{array}{c}\text { Where } \\
\text { (Dimana) }\end{array}$ & $\begin{array}{c}\text { Dilaksanakan di Perusaaan ban di Jawa Barat, } \\
\text { tepatnya di ruang area produksi dan ruang area QC }\end{array}$ \\
\hline $\begin{array}{c}\text { Sekuens } \\
\text { (Urutan) }\end{array}$ & $\begin{array}{c}\text { When } \\
\text { (Kapan) }\end{array}$ & Pada saat proses produksi \\
\hline Orang & $\begin{array}{c}\text { Who (Siapa) } \\
\text { engenering }\end{array}$ \\
\hline Metode & $\begin{array}{c}\text { How } \\
\text { (Bagaimana) }\end{array}$ & Pemasangan alat sensor alarm scalling pada carbon \\
\hline
\end{tabular}

Tabel 12. Usulan Perbaikan Menggunakan Metode $5 \mathrm{~W}+1 \mathrm{H}$

\begin{tabular}{|c|c|c|}
\hline Jenis & $5 \mathrm{~W}+1 \mathrm{H}$ & Deskrpsi Rencana Perbaikan \\
\hline $\begin{array}{l}\text { Tujuan } \\
\text { Utama }\end{array}$ & What (Apa) & Menurunkan reject compound AT-807 \\
\hline $\begin{array}{c}\text { Alasan } \\
\text { Kegunaan }\end{array}$ & $\begin{array}{c}\text { Why } \\
\text { (Mengapa) }\end{array}$ & $\begin{array}{l}\text { Agar Proses Produksi sesuai dengan prosedur kerja } \\
\text { yang telah ditetapkan sehingga mengasilkan produk } \\
\text { baik tanpa reject dan sesuai spesifikasi }\end{array}$ \\
\hline Lokasi & $\begin{array}{c}\text { Where } \\
\text { (Dimana) }\end{array}$ & $\begin{array}{c}\text { Dilaksanakan di Perusaaan ban di Jawa Barat, } \\
\text { tepatnya di ruang area produksi }\end{array}$ \\
\hline $\begin{array}{l}\text { Sekuens } \\
\text { (Urutan) }\end{array}$ & $\begin{array}{l}\text { When } \\
\text { (Kapan) }\end{array}$ & Pada saat proses produksi \\
\hline Orang & Who (Siapa) & $\begin{array}{c}\text { Tanggung jawab diserakan kepada operator produksi, } \\
\text { engenering }\end{array}$ \\
\hline Metode & $\begin{array}{c}\text { How } \\
\text { (Bagaimana) }\end{array}$ & Pemasangan alat sensor alarm scalling pada oil \\
\hline
\end{tabular}

Tabel 13. Usulan Perbaikan Menggunakan Metode $5 \mathrm{~W}+1 \mathrm{H}$

\begin{tabular}{|c|c|c|}
\hline Jenis & $5 \mathrm{~W}+1 \mathrm{H}$ & Deskrpsi Rencana Perbaikan \\
\hline $\begin{array}{l}\text { Tujuan } \\
\text { Utama }\end{array}$ & What (Apa) & Menurunkan reject compound AT-807 \\
\hline $\begin{array}{c}\text { Alasan } \\
\text { Kegunaan }\end{array}$ & $\begin{array}{c}\text { Why } \\
\text { (Mengapa) }\end{array}$ & $\begin{array}{l}\text { Agar Proses Produksi sesuai dengan prosedur kerja } \\
\text { yang telah ditetapkan sehingga mengasilkan produk } \\
\text { baik tanpa reject dan sesuai spesifikasi }\end{array}$ \\
\hline Lokasi & $\begin{array}{c}\text { Where } \\
\text { (Dimana) }\end{array}$ & $\begin{array}{l}\text { Dilaksanakan di Perusaaan ban di Jawa Barat, } \\
\text { tepatnya di ruang area produksi }\end{array}$ \\
\hline $\begin{array}{l}\text { Sekuens } \\
\text { (Urutan) }\end{array}$ & $\begin{array}{l}\text { When } \\
\text { (Kapan) }\end{array}$ & Pada saat proses produksi \\
\hline Orang & Who (Siapa) & $\begin{array}{l}\text { Tanggung jawab diserakan kepada operator } \\
\text { produksi, engenering }\end{array}$ \\
\hline Metode & \begin{tabular}{c|} 
How \\
(Bagaimana)
\end{tabular} & $\begin{array}{l}\text { Pembuatan sistem blocking penibangan secara } \\
\text { automatis }\end{array}$ \\
\hline
\end{tabular}

Tabel 14. Usulan Perbaikan Menggunakan Metode $5 \mathrm{~W}+1 \mathrm{H}$

\begin{tabular}{|c|c|c|}
\hline Jenis & $5 \mathrm{~W}+1 \mathrm{H}$ & Deskrpsi Rencana Perbaikan \\
\hline $\begin{array}{c}\text { Tujuan } \\
\text { Utama }\end{array}$ & What (Apa) & Menurunkan reject compound AT-807 \\
\hline $\begin{array}{c}\text { Alasan } \\
\text { Kegunaan }\end{array}$ & $\begin{array}{c}\text { Why } \\
\text { (Mengapa) }\end{array}$ & $\begin{array}{c}\text { Agar Proses Produksi sesuai dengan prosedur kerja } \\
\text { yang telah ditetapkan sehingga mengasilkan produk } \\
\text { baik tanpa reject dan sesuai spesifikasi }\end{array}$ \\
\hline Lokasi & $\begin{array}{c}\text { Where } \\
\text { (Dimana) }\end{array}$ & $\begin{array}{c}\text { Dilaksanakan di Perusaaan ban di Jawa Barat, } \\
\text { tepatnya ruang area QC }\end{array}$ \\
\hline $\begin{array}{c}\text { Sekuens } \\
\text { (Urutan) }\end{array}$ & $\begin{array}{c}\text { When } \\
\text { (Kapan) }\end{array}$ & Pada saat proses Quality Control \\
\hline Orang & $\begin{array}{c}\text { Who (Siapa) } \\
\text { Metode }\end{array}$ & $\begin{array}{c}\text { Tanggung jawab diserakan kepada insperctor Quality } \\
\text { Control }\end{array}$ \\
\hline (Bagaimana) & $\begin{array}{c}\text { Pembuatan IKL yang ditujuan kepada Quality } \\
\text { Control untuk adanya pengecekan material sebelum } \\
\text { masuk ke proses produksi setelah serah terima } \\
\text { material oleh pihak gudang material }\end{array}$ \\
\hline
\end{tabular}

Tabel 15 Usulan Perbaikan Menggunakan Metode $5 \mathrm{~W}+1 \mathrm{H}$

\begin{tabular}{|c|c|c|}
\hline Jenis & $5 \mathrm{~W}+1 \mathrm{H}$ & Deskrpsi Rencana Perbaikan \\
\hline $\begin{array}{l}\text { Tujuan } \\
\text { Utama }\end{array}$ & What (Apa) & Menurunkan reject compound AT-807 \\
\hline $\begin{array}{c}\text { Alasan } \\
\text { Kegunaan }\end{array}$ & $\begin{array}{c}\text { Why } \\
\text { (Mengapa) }\end{array}$ & $\begin{array}{l}\text { Agar Proses Produksi sesuai dengan prosedur kerja } \\
\text { yang telah ditetapkan sehingga mengasilkan produk } \\
\text { baik tanpa reject dan sesuai spesifikasi }\end{array}$ \\
\hline Lokasi & $\begin{array}{l}\text { Where } \\
\text { (Dimana) }\end{array}$ & $\begin{array}{c}\text { Dilaksanakan di Perusaaan ban di Jawa Barat, } \\
\text { tepatnya ruang area QC }\end{array}$ \\
\hline $\begin{array}{l}\text { Sekuens } \\
\text { (Urutan) }\end{array}$ & $\begin{array}{l}\text { When } \\
\text { (Kapan) }\end{array}$ & Pada saat proses Quality Control \\
\hline Orang & Who (Siapa) & $\begin{array}{l}\text { Tanggung jawab diserakan kepada insperctor Quality } \\
\text { Control }\end{array}$ \\
\hline Metode & $\begin{array}{c}\text { How } \\
\text { (Bagaimana) }\end{array}$ & $\begin{array}{l}\text { Pembuatan IKL yang ditujukan kepada Quality } \\
\text { Control untuk adanya pengecekan parameter secara } \\
\text { berkala }\end{array}$ \\
\hline
\end{tabular}

\section{Tahap Control}

Rencana tindakan perbaikan yang dilakukan di Perusahaan ban di Jawa barat akan dilaksanakan dalam jangka waktu 4 bulan kedepan dimuali dari Januari sampai dengan bulan April 2019 sehingga dapat mencapai target yang diinginkan perusahaan. adanpun perencanaan yang berupa alat kontrol untuk mengetaui apakah ada peningkatan kualitas pembuatan produk compound AT-807 dengan cara:

1. Selalu sosialisasi terhadap operator produksi setiap awal breafing;

2. Pengawasan pada mesin secara ketat untuk menghindari perubahan setelan mesin secara otomatis atau mengoperasikan mesin sesuai dengan SOP (standar operasional prosedur) yang baru; dan

3. Melakukan pengawasan bahan baku oleh bagian karyawan produksi dan Qc agar mutu barang yang dihasilkan berkualitas.

Tabel 16. Perbandingan Jumlah Produksi dan Reject Sebelum Perbaikan dan Sesudah Perbaikan

\begin{tabular}{|c|c|c|c|c|c|c|}
\hline \multirow{2}{*}{ NO } & ITEM & $\begin{array}{c}\text { KONDISI } \\
\text { SEBELUM }\end{array}$ & \multicolumn{3}{|c|}{$\begin{array}{c}\text { SELAMA PROSES PERBAIKAN } \\
\text { PERJALAN }\end{array}$} \\
\cline { 5 - 7 } & & PERBAIKAN & Jan-19 & Feb-19 & Mar-19 & Apr-19 \\
\hline 1 & $\begin{array}{c}\text { Rata-Rata Jumlah } \\
\text { Produksi }\end{array}$ & 5319 & 5520 & 5341 & 5246 & 5104 \\
\hline & $\begin{array}{c}\text { Rata-Rata Reject } \\
\text { compound AT- } \\
807\end{array}$ & 1910 & 1670 & 1141 & 726 & 481 \\
\hline & Persentase & $35,9 \%$ & $30,3 \%$ & $21,4 \%$ & $13,8 \%$ & $9,4 \%$ \\
\hline Level Sigma & 3,20 & 3,28 & 3,44 & 3,62 & 3,77 \\
\hline Yield & $64 \%$ & $70 \%$ & $79 \%$ & $86 \%$ & $91 \%$ \\
\hline
\end{tabular}

\section{KESIMPULAN}

Pengendalian kualitas dengan metode six sigma merupakan pengendalian kualitas yang dilakukan secara terus menerus, dengan harapan dapat memperbaiki kualitas produk reject atau cacat. Peneliti telah menerapkan 
metode six sigma di perusahaan ban di jawa barat yang bergerak dalam produksi aneka jenis ban.Berikut adalah hasilnya:

1. Lima akar masalah yang menjadi faktor penyebab produk reject atau cacat dianalisa dengan menggunakan alat diagram sebab akibat, faktor-faktor tersebut yaitu (1) man (pekerja) diantaranya belum adanya IKL (Instruksi Kerja Lapangan) untuk pengecekan parameter proses secara bekala oleh pihak QC dan operator belum paam tentang efek penimbangan material ke conveyor secara sistem manual, (2) material (bahan baku) diantaranya tidak adanya standarisasi pengecekan material oleh pihak QC, (3) machine (mesin) diantaranya tidak adanya alat monitoring pendingin mesin mixer saat proses compound, tidak adanya sensor alarm untuk menditeksi saat carbon over maupun under dari spesifikasi, dan tidak adanya sensor alarm untuk menditeksi saat oil over maupun under dari spesifikasi, (4) method (metode) diantaranya tidak adanya bloking sistem penimbangan automatis saat penimbangan material ke conveyor.

2. Setelah dilakukanya tahap define compond AT-807 adalah compond yang paling tinggi jumlah reject dibandingkan dengan jenis compound yang lain. Pada setelah dilakukannya perhitungan tahap measure, diketahui bahwa cacat terbesar

\section{DAFTAR PUSTAKA}

Aziza, Nurul; Afandi, Muhammad;. (2018, Juni). Analisis Defect dan Kualitas Produk Writing And Printing Paper Dengan Six Sigma. Engineering and Sains, II (1), 73-78.

Bos, Aat Van den; Kemper, Benjamin; Waal, Vincent De;. (2014). A Study On How To Improve The Through Out Time Of Lean Six Sigma Projects In A Construction Company. International Journal of Lean Six Sigma, V(2), 212-226.

Dambhare, Sunil; Aphale, Siddhant; Kakade, Kiran; Thote, Tejas; Borade, Atul;. (2013). Productivity Improvement of a Special Purpose Machine Using DMAIC Principles: A Case Study. Journal of yang dialami oleh perusahaan adalah pada jenis compound AT-807 dengan hasil reject tertinggi. Nilai sigma ratarata 3,20, dengan nilai ini cukup tinggi dalam skala kemungkinan tanpa cacat. Maka perlu adanya perbaikan secara bertahap sehingga mencapai nilai sigma 6 dimana skala kemungkinan tanpa cacat adalah 99,9997\%. Pada tahap analisa menggunakan diagram pareto, diketahui bahwa jenis cacat yang memiliki jumlah reject terbesar didominasi oleh jenis reject viskositas, dengan persentase sebesar $49 \%$.

3. Usulan perbaikan yang diusulkan peneliti berupa Pemasangan alat monitoring temperatur pendingin mesin, pemasangan alat sensor alarm scaling pada carbon, pemasangan alat sensor alarm scaling pada oil, pembuatan sistem bloking penimbangan aotumatis, pembuatan IKL yang ditujuan kepada Quality Control untuk adanya pengecekan material sebelum masuk ke proses produksi setelah serah terima material oleh pihak gudang material, pembuatan IKL yang ditujukan kepada Quality Control untuk adanya pengecekan parameter secara berkala dan jelas pembagian schedulenya untuk pengecekan parameter compound secara berkala.

Quality and Reliability Engineering, 113.

Dewi, Shanti Kusuma;. (2012, Februari). Minimasi Defect Produk Dengan Konsep Six Sigma. Jurnal Teknik Industri, XIII (1), 43-50.

Ekoanindiyo, Firman Ardiansyah. (2014, Januari). Pengendalian Cacat Produk Dengan Pendekatan Six Sigma. Jurnal Dinamika Teknik, VIII(1), 35 - 43.

Harahap, Bonar; Parinduri , Luthfi; Fitria, An Ama Lailan;. (2018, Mei). Analisis Pengendalian Kualitas Dengan Menggunakan Metode Six Sigma PT. Growth Sumatra Industry. Buletin Utama Teknik, XIII(3), 211-219.

Hendi Tannadi. (2015). Pengendalian Kualitas. Yogyakarta: Graha Ilmu. 
Irwan, \& Haryono, D. (2015). Pengendalian Kualitas Statistik. Bandung: Alfabeta Cv.

Napitupulu, Monica Elisa; Hati, Shinta Wahyu;. (2018, Maret). Analisis Pengendalian Kualitas Produk Garment Pada Project In Line Inspector Dengan Metode Six Sigma Di Bagian Sewing Produksi Pada PT Bintan Bersatu Apparel Batam. Journal of Applied Business Administration, II(1), 29-45.

Prabu, K., Makesh, J., Raj, K. N., \& Devadasan, S. (2013). Six Sigma Implementation Through DMAIC: A Case Study. Int. J. Process Management and Benchmarking, III(3), 386-400.

S. Arun Vijay. (2014, Februari 25). Reducing And Optimizing The Cycle Time Of Patients Discharge Process In A Hospital Using Six Sigma Dmaic Approach. International Journal for Quality Research, VIII(2), 169-182.

Sin, Tan Chan; Usubamatov, Ryspek; Amin Hamzas, Mohd Fidzwan B.Md.; Wai, Low Kin; Yao, Teh Keat; Bahari, Muhammad Syahril;. (2014). Parameters Investigation of Mathematical Model of Productivity for Automated Line with Availability Aziza, Nurul; Afandi, Muhammad;. (2018, Juni). Analisis Defect Dan Kualitas Produk Writing and Printing Paper Dengan Six Sigma. Engineering and Sains, II(1), 73-78.
Tenny, Baguna; Tamengkel, Lucky F.; Mukuan, Danny D. S.;. (2018). Analisis Pengendalian Kualitas Mutu Produk Sebelum Eksport Dengan Mengunakan Metode Six Sigma Pada PT. Nichindo Manado Suisan. Jurnal Administrasi Bisnis, VI(4), 28-35.

Vitho, Ivan; Ginting, Elisabeth; , Anizar;. (2013, November). Aplikasi Six Sigma Untuk Menganalisis Faktor Faktor Penyebab Kecacatan Produk Crumb Rubber SIR 20 Pada PT. XYZ. e-Jurnal Teknik Industri FT USU, III(4), 23-28.

Widodo, T., \& P, H. (2015, September). Analisa Pengendalian Kualitas Resin ABC Menggunakan Six Sigma Di PT. Pardic Jaya Chemicals. Teknik, Vol.4, No. 2.

Wisnu Broto, Pertrus; Rukmana, Arya; (2015, Juni). Pengendalian Kualitas Produk Dengan Pendekatan Six Sigma Dan Analisis Kaizen Serta New Seven Tools Sebagai Usaha Pengurangan Kecacatan Produk. Jurnal Teknologi, XXXIII(1), 65-74.

Yunitasari, Elly Wuryaningtyas; Nurhayati, Emmy;. (2017, Agustus). Pendekatan Lean Six Sigma Dan Taguchi Untuk Mengatasi Masalah Pengemasan Dan Pemasaran Produk Wedang Uwuh Instan Sruput. Jurnal Science Tech, III(2), 127136. 